\title{
Foam Generation in a Rotor-Stator Mixer
}

\author{
Schaumerzeugung in einem Rotor-Stator Mischer
}

\author{
A. B. J. KROEZEN, J. GROOT WASSINK and E. BERTLEIN \\ University of Twente, Department of Chemical Engineering, P.O. Box 217, 5700 AE Enschede (The \\ Netherlands)
}

(Received December 28, 1987; in final form October 10, 1988)

\begin{abstract}
The foaming process of an aqueous liquid system with surface active agents and thickeners in a rotor-stator mixer has been studied.

The foaming capacity of a rotor-stator mixer may be represented by a so-called mixing characteristic. The foamabilities of several liquid systems have been measured as a function of the mixer geometry and the rotational speed.

The hydrodynamics in a rotor-stator mixer is characterized by a Newton-Reynolds relationship. The mechanism of foaming and the dependence of several mixing parameters are different for the turbulent and laminar flow regions. The mixing process is evaluated in both regimes. In the transition region from turbulent to laminar the foaming is very poor in comparison with that in the turbulent and laminar flow regimes.
\end{abstract}

\section{Kurzfassung}

Unter Verwendung von Tensiden und Verdickungsmitteln wurde der Schäumungsvorgang einer wasserhaltigen Flüssigkeit in einem Rotor-Stator Mischer untersucht. Die Schaumkapazität eines Rotor-Stator Mischers kann mit Hilfe einer sog. Mischungscharakteristik dargestellt werden. Die Schäumungsfähigkeit mehrer Flüssigkeitssysteme wurde bestimmt in Abhängigkeit von der Geometrie und der Umfangsgeschwindigkeit des Mischers.

Die Hydrodynamik in einem Rotor-Stator Mischer wird mit einem sog. Newton-Reynolds Zusammenhang charakterisiert.

Der Mechanismus des Schäumens und die Abhängigkeit von verschiedenen Mischungsparametern sind bei turbulenter bzw. laminarer Strömung verschieden. Sowohl für den turbulenten als auch für den laminaren Bereich wurde der Mischungsprozeß untersucht. Es stellte sich heraus, daß im Übergangsbereich von turbulent zu laminar das Schäumen schlechter ist als im laminaren oder im turbulenten Bereich.

\section{Synopse}

Rotor-Stator Mischer sind bekannt wegen ihrer Anwendung bei der Herstellung von Gas-Flüssigkeitsdispersionen oder Schäumen, insbesondere im Bereich der Applikation von Chemikalien auf poröse Substrate wie Textilien, Teppiche und Non-wovens.

Die Mischer können kontinuierlich betrieben werden, wobei Gas und Flüssigkeit an einer Seite des Apparates zugeführt und der Schaum an der anderen Seite abgeführt wird.

Der Rotor-Stator Mischer besteht aus einer Welle, die zentral in ein zylindrisches Gehäuse eingebaut ist; Rotorringe an der Welle und Statorringe am Gehäuse bilden eine Reihe von elementaren Mischzellen (Bilder $I$ und 2). Die verschiedenen Ausführungsformen der
Mischer sind in Tabelle 1 zusammengestellt, die Zusammensetzung und die Viskosität der angewandten Flüssigkeitssysteme sind in Tabelle 2 angegeben.

Zwei wichtige Parameter beim Schäumen sind die Mischungskapazität und die Verteilung der Gasblasen im Schaum [7]. Die Mischungskapazität kann in einer sogenannten Mischkurve zwischen homogenem und inhomogenem Schaum dargestellt werden (Bild 3). Wenn der Schaum bei verhältnismäßig hohem Druck im Mischer hergestellt wird, dann kann durch Expansion die Mischungskapazität vergrößert werden (Gl. (1)).

Im Mischer sind zwei Phasen zu erkennen: eine Gas- und eine Schaumphase. Die Gasphase bildet einen Kegel rund um die Welle, wird von den Rotoren zerschlagen und in die Schaumphase geführt (Bilder 4 und 5). Wenn der Gaskegel sich bis zum Ende der 
Welle ausbreitet, wird die Gasphase nicht genügend zerteilt und in der Schaumphase vermischt, sodaß 'Blow-by' auftritt.

Der Einfluß der Zahl der Mischungszellen auf die Mischkurve wird dargestellt in Bild 6. Bild 7 gibt eine Übersicht über die Schaumdichte in Abhängigkeit von der Höhe des Mischers.

Die Energiedissipation im Mischer wird hauptsächlich von der Strömung um die Rotoren bestimmt. Messungen des Drehmomentes an der Welle wurden für 8 verschiedene Abmessungen des Mischers durchgeführt (Gl. (2)). Es wurd ein Newton-Reynolds Zusammenhang gefunden, der für alle Abmessungen eine gute Näherung darstellt (Gl. (3) und (4)). Sowohl die Newton-als auch die Reynoldszahl wurden modifiziert in den Gl. (5), (7) und (8) dargestellt. In Bild 8 sowie in den Bildern 9 und 10 sind die Versuchsergebnisse für den turbulenten bzw. für den laminaren Bereich angegehen. In den GI. (11) und (12) wird die Newton-Reynolds Beziehung im laminaren Bereich in zwei Faktoren getrennt, und in den Beziehungen (13) und (14) wird eine Mischungskonstante $K$ definiert, um die Viskosität des pseudoplastischen Schaumes für die Reynoldszahl berechnen zu können. Die Reynoldszahl nimmt in Abhängigkeit von der Mischerhöhe ab, weil die Dichte abnimmt und die Viskosität zunimmt.

Die Bestimmung einer großen Zahl von Mischungskurven für verschiedene Flüssigkeitssysteme und die Berechnung der dazu gehörenden lokalen Rcynoldszahlen führte zu einer Aufteilung der Güte der Schaummischer in drei Stufen:

\begin{tabular}{lll}
\hline Strömungsbereich & Reynoldszahl & Mischung \\
\hline Turbulent & $>0,15$ & Gut \\
Übergang & $0,02<\mathrm{Re}<0,15$ & Schlecht \\
Laminar & $<0,02$ & Mäßig gut \\
\hline
\end{tabular}

Der Mechanismus der Mischung im laminaren unterscheidet sich von dem im turbulenten Bereich. In diesem Beitrag werden Mischungskurven angegeben in Abhängigkeit von der Umdrehungszahl des Mischers für verschiedene Mischer und Flüssigkeitssysteme (Bilder 9 bis 13).

\section{Introduction}

Rotor-stator mixers are used for on-line production of colloidal gas-liquid dispersions called foams. In this article, the study of the influence of the hydrodynamics in a rotor-stator mixer on the foaming process will be described.

One of the uses of rotor-stator mixers is in the production of foam, which is used as an intermediate to apply chemicals on porous materials (textiles, carpets, non-wovens). By using foam as the application medium, the quantity of solvents necessary to achieve a homogeneous distribution can be considerably reduced. Consequently, the costs of drying after the application process can be reduced [1-3].
In the rotor-stator mixer, a gas phase and a liquid phase containing surfactants are mixed by the applied kinetic energy. Rotor-stator mixers are continuous mixers with a relatively small mixing volume and a large mixing intensity. Foams are also produced in static mixers. In a rotor-stator mixer the energy is supplied by the rotation pins in the foam phase; in the static mixer the energy dissipation is determined by the pressure drop which arises in the mixing column as a result of the flow of gas and liquid. The quantity of energy supplied in the static mixer, and therefore the foam structure obtained depend, however, on the foam production rate. Rotor-stator mixers can be utilized over a greater production range, and can, in general, also be applied over a larger range of liquid systems to be foamed, in particular systems with a high liquid viscosity.

In this article, the following aspects of the foaming process will be discussed. In the first part, a general characterization of the mixing process and an overview of the varied parameters with respect to the geometry in the mixer and the liquids used will be given. In the second part, the hydrodynamics and the energy dissipation in the mixer will be evaluated more closely. In the third part, the hydrodynamics are related to the foaming rate for the diverse liquid systems. Finally, the influence of a number of variations of the mixer geometry on the hydrodynamics and the foaming process will be discussed.

\section{Overall description of foam generation in rotor-stator mixers}

\subsection{Foamability and foum stability}

Foams are colloidal gas emulsions, the gas being the dispersed and the liquid the continuous phase. In particular, gas emulsions having a high volume fraction of gas $(50->90 \mathrm{vol} . \%)$ are called foams. The structure of foam may be characterized by the blow ratio, which is the volumetric gas/liquid ratio, and the bubble size distribution. Owing to the high surface energy and under the influence of the gravitational field, foams are thermodynamically unstable. The deterioration of the foam is caused by a number of different mechanisms [4-6]: firstly, by drainage under the influence of gravity, complete separation between the liquid and the foam structure occurs; secondly, by diffusion of the gas via the lamellae from small to relatively large bubbles owing to the pressure difference between them, a steady increase in the bubble size results; thirdly, by coalescence of bubbles or destruction of the lamellae an increase in the bubble size occurs.

The rate of destabilization of foam is greatly dependent on the bulk and surface-active properties of the liquid applied, on the structure of foam, and on the external mechanical or thermal conditions.

Foamability is a term which indicates the ease of formation of foam from a gas and a liquid when a given amount of kinetic energy is supplied. In the 
literature, different laboratory tests are described to measure the foamability of a given product system. The translation and applicability of these results to the mixing process in a rotor-stator mixer are rather poor [6]. Foamability is not only dependent on the properties of the product system used (gas, liquid, tensides, additives) but also on the process conditions applied in the mixer. That is why foamability has to be considered as a process relationship between product system and mixing equipment, so it will be represented here by a mixing characteristic for the foaming process in a rotor-stator mixer.

Foamability may be described as the net result of distribution of the gas over the foam phase and the ability to stabilize the structure formed under dynamic conditions.

The mechanism of destabilization under dynamic conditions (that is, during the generation in the mixer) is quite different from destabilization under static conditions.

The mixing process can be characterized by the blow ratio and bubble size distribution of the foam produced. The blow ratio can be determined directly from the ratio of the gas and liquid flow rates supplied to the mixer. The mixing capacity is determined hy the region utilized by the flow rates in which the supplied gas and liquid flows are mixed to one homogeneous foam. The boundaries of the working area of the flow rates of the mixing process may be viewed as a measure of the foamability given the pertaining process conditions.

The bubble diameter distribution of the foam is the second process-determining parameter. This parameter is mainly determined by the shear forces in the mixer and can be described by the Weber number [7]. The influence of the hydrodynamics on the working area of the mixing process will be considered in more detail in the following discussion.

\subsection{Mixer geometry}

The investigations on foam production were carried out in a so-called rotor-stator mixer. The mixing chamber consists of an annular space between a stationary shell and a rotating shaft. In the annular space a number of mixing cells are formed by rotor elements fixed on the rotating shaft and stator elements connected to the shell of the mixer. The mixing elements each have a number of pins evenly distributed over their periphery. The mixing space depends on the number of rotor-stator elements installed in the mixer and is easily changed by variation of that number. When decreasing the number of mixing cells, small blocks were used to fill up the space between the adjacent cells.

An elementary mixing cell consisting of one rotor and one stator device will be defined as one rotorstator unit.

In the mixer used, gas and liquid are continuously fed to the mixer at one side and the foam is removed from the mixer at the opposite side. A cross-section of the mixer is represented in Fig. 1. The construction of part of the rotor-stator unit is given in Fig. 2.

In the experiments, different variations of the dimensions of the elementary unit have been studied. Geometry 1 is the basic geometry, from which the different variations were studied. The dimensions varied are the distance between the rotor and the stator pin, $p$, the height of a rotor and stator pin, $q$, the number of pins on a rotor, $i$, and the diameter of the annular space, $L$. The total mixing volume of the different geometries was kept nearly the same. The different dimensions of the mixers used are given in Table 1 .

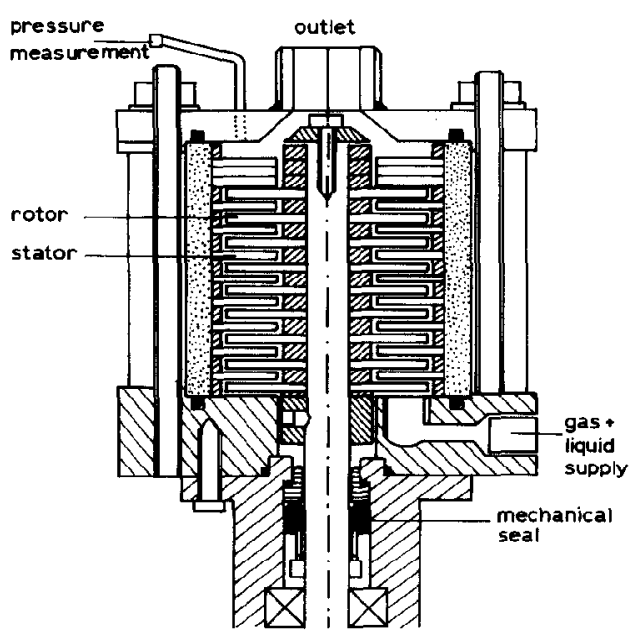

Fig. 1. Lay-out of the mixer.

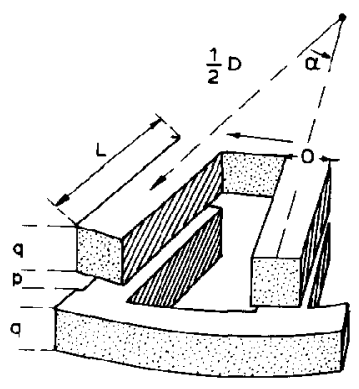

Fig. 2. Elementary mixer unit.

TABLE 1. Mixer dimensions

\begin{tabular}{|c|c|c|c|c|c|c|c|}
\hline \multirow{2}{*}{$\begin{array}{l}\text { Mixer } \\
\text { No. }\end{array}$} & \multicolumn{7}{|c|}{ Dimensions (mm) } \\
\hline & $D$ & $L$ & $i$ & $p$ & $q$ & $h$ & $o$ \\
\hline 1 & 45 & 17 & 18 & 1 & 3 & 10 & 3 \\
\hline 2 & 45 & 17 & 18 & 2 & 3 & 8 & 3 \\
\hline 3 & 45 & 17 & 18 & 1 & 1.5 & 17 & 3 \\
\hline 4 & 45 & 17 & 18 & 2 & 1.5 & 12 & 3 \\
\hline 5 & 45 & 17 & 18 & 1 & 4.5 & 7 & 3 \\
\hline 6 & 45 & 17 & 18 & 2 & 4.5 & 6 & 3 \\
\hline 7 & 45 & 17 & 9 & 1 & 3 & 10 & 3 \\
\hline 8 & 38 & 10 & 18 & 1 & 3 & 10 & 3 \\
\hline
\end{tabular}


The mixers which were studied are smaller than those used in industry. Our mixers have a smaller diameter $D$ and fewer rotor-stator units $h$. The other geometrical dimensions are the same as for industrial mixers [8].

\subsection{The product systems}

In the experiments, air was used as the gas phase, and water with additional compounds was used as the liquid phase. A constant concentration of tenside and a varying concentration of thickener were applied to the water phase. Two different products were used as the surfactant, Diphasol EA/VA $(1.5 \%$ Diphasol EA, $1 \%$ Diphasol VA, $0.1 \%$ acetic acid) and lauryl sulphate $(1 \%)$. Diphasol EA/VA is a tenside mixture from Ciba Geigy with intermediate foaming properties; lauryl sulphate is a tenside with a much stronger foaming capacity.

As a thickener, Solvitose Fn (a starch ether) was used and added in different concentrations. The different product formulations are given with their respective codes in Table 2 .

TABLE 2. Product formulation and code

\begin{tabular}{llll}
\hline $\begin{array}{l}\text { Product } \\
\text { system }\end{array}$ & Tenside & Thickener & $\begin{array}{l}\text { Viscosity } \\
\left(\mathrm{Pa} \mathrm{s}, 20^{\circ} \mathrm{C}\right)\end{array}$ \\
\hline Di-0 & Diphasol EA/VA & - & 0.0012 \\
Di-40 & Diphasol EA/VA & $40 \mathrm{~g}^{-1}$ Solvitose & $2.7 D_{\mathrm{r}}^{-0.45}$ \\
Ls-30 & Lauryl sulphate & $30 \mathrm{~g}^{1}{ }^{1}$ Solvitose & $12 D_{\mathrm{r}}{ }^{-0.55}$ \\
\hline
\end{tabular}

\subsection{The mixing characteristic}

Foamability of a given liquid system in a rotorstator mixer is limited by the maximum amount of gas per amount of liquid which can be dispersed to a homogeneous foam. Exceeding the maximum gas now leads to a heterogeneous foam in which large bubbles of unmixed gas are observed; the pertinent phenomenon is called blow-by.

The performance of a foam mixer may be expressed in a mixing characteristic in which the actual gas flow $F_{\mathrm{G}}$ is given as a function of the liquid flow $F_{\mathrm{L}}$. The mixing characteristic can be defined as the $F_{\mathrm{G}}$ versus $F_{\mathrm{L}}$ boundary curve below which a homogencous foam is produced and beyond which blowby is observed. As already mentioned before, the mixing characteristic is not only a measure of mixer performance but is also greatly dependent on the product system properties. An example of a mixing characteristic is given in Fig. 3.

The mixing characteristic is determined experimentally by slowly increasing the gas flow at different, but for each experiment fixed, values of the liquid flow. The transition of a homogeneous to a heterogeneous foam is easily observed visually, giving rise to a point on the mixing characteristic for each set of experiments. The maximum blow ratio for a given liquid flow may be determined from the

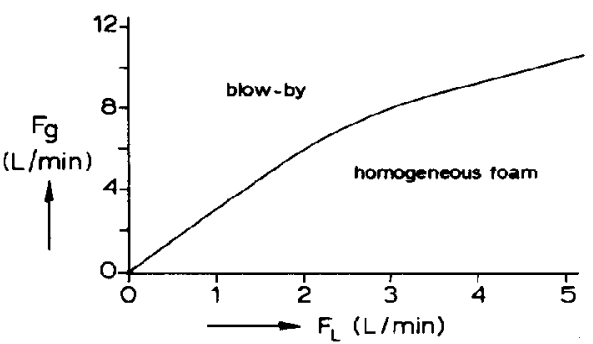

Fig. 3. Mixing characteristic (geometry $1,1200 \mathrm{rev} \min ^{-1}$, system Di-0).

corresponding point on the mixing characteristic. For the example in Fig. 3 the maximum blow ratio for relatively low values of liquid flow is constant, being of the order of 4; at higher flows the maximum blow ratio decreases at increasing values of $F_{\mathrm{L}}$.

Focusing on mixer pressure, it can be stated that, owing to pressure losses in pipes and fittings, foam generation takes place under a given over-pressure. Therefore the blow ratio in the mixer is substantially lower than the blow ratio at the end of the piping system where the gas is expanded to atmospheric pressure. Under the circumstances in our experiments, the expansion of the gas phase may be calculated by assuming the gas is a compressible ideal gas and the liquid is incompressible [7]. If the foam in the mixer at a pressure $P_{\mathrm{m}}$ is expanded to a foam with a blow ratio $B_{0}$ and a pressure $\boldsymbol{P}_{0}$, then the blow ratio in the mixer can be calculated by

$B_{\mathrm{m}}=B_{0}\left(P_{0} / P_{\mathrm{m}}\right)$

Thus the capacity of the foam mixer may be increased substantially if the foaming process is carried out under a certain over-pressure. In a mixing characteristic the actual maximum gas flow $\left(1 \mathrm{~min}^{-1}\right.$ at $P_{\mathrm{m}}$ ) is given as a function of $F_{\mathrm{L}}$. The mixing characteristic is therefore independent of mixer pressure and for practical use the maximum foaming capacity can be calculated with eqn. (1) and the mixing characteristic.

Given a certain set of mixing conditions and the product system, the mixing capacity can be represented by a mixing characteristic. The mixing characteristic is an overall quantity of the mixing process. In the following paragraphs, the mixing process will be discussed in more detail.

\section{Hydrodynamies}

\subsection{Energy consumption in rotor-mixer stators}

In the annular mixing space a gas and a liquid are converted to a homogeneous foam flow. By closely observing the distribution of the gas and liquid phases in the mixer under stationary process conditions, the following mechanism of dispersion can be recognized (see Fig. 4).

It is more accurate to speak of a gas phase and a foam phase in the mixer, than of a gas phase and a 

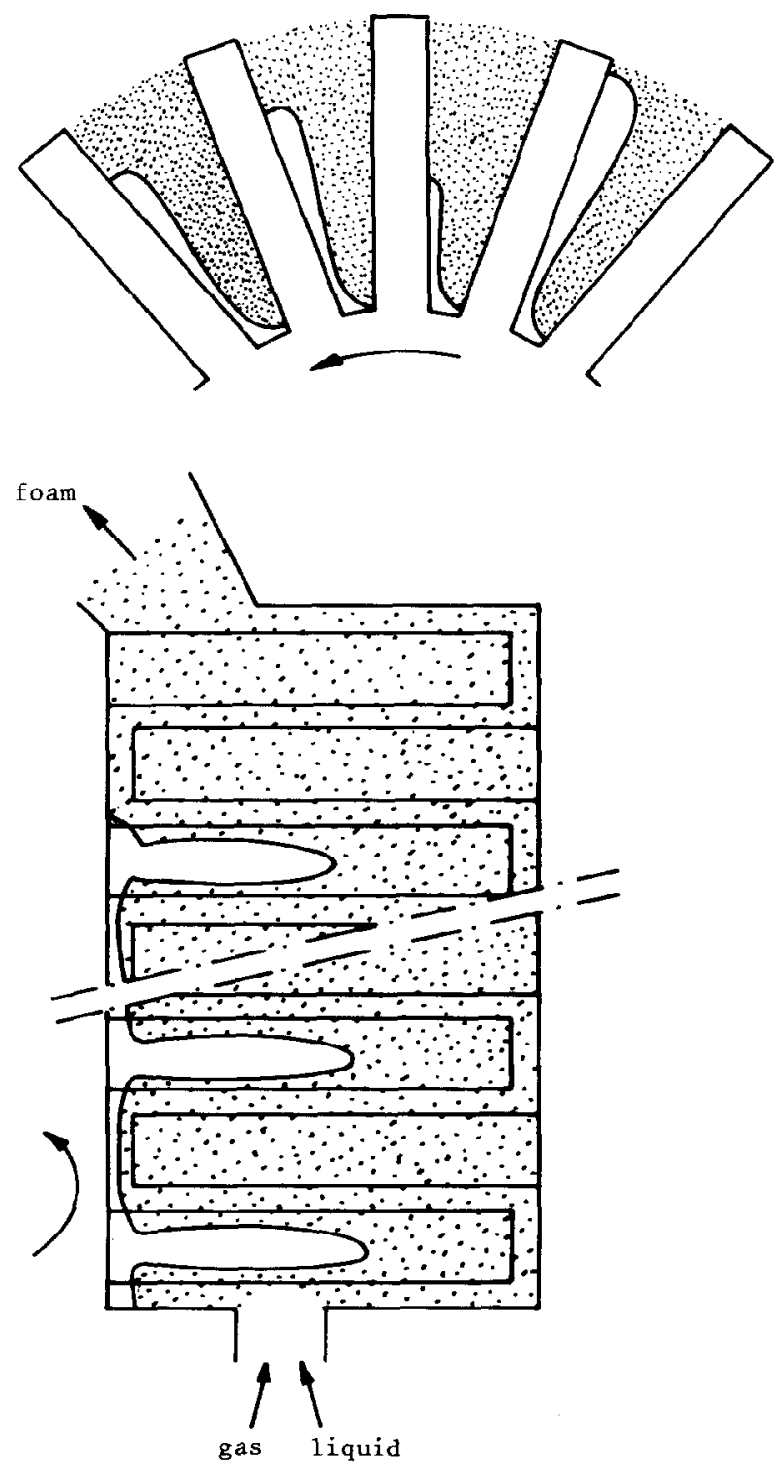

Fig. 4. Hydrodynamics in the mixer; the upper diagram shows the air conus around the shaft and cavities behind the pins.

liquid phase. As a result of the centrifugal field in the mixer, the air collects as a thin air conus around the shaft. The rest of the annular space is filled with the foam phase, which moves more or less as a plug flow through the mixer in the axial direction. The mixing process consists of dispersing air from the gas conus into the foam phase. The blow ratio of the foam increases from the bottom to the top of the mixer, since each rotor-stator unit disperses an additional amount of air in the foam. The number of rotorstator units over which the gas conus extends depends on the mixing capacity of each rotor-stator unit and the quantity of gas supplied. If the gas flow is rather small, the gas conus extends only over a few rotor-stator units. The blow ratio of the foam will change over a limited number of rotor-stator units and then remain constant, since no additional air will be dispersed. If the supplied gas flow is large, all the rotor stator units combined will be unable to disperse the gas. The air conus then extends to the top of the mixer, and non-dispersed air leaves the mixer (blow-by).

The mixing of air from the gas conus occurs by the dispersion of air from a cavity behind the rotor pins. As a result of the rotation of the rotor pins, a local under-pressure occurs at the back of the rotor pins. The gas flows from the gas conus to the cavity behind the rotor pins and is dispersed in the foam phase.

As well as the mixing of air into the foam, the bubble size of the dispersed air is decreased. The reduction in bubble size is primarily due to the shear forces which occur in the homogeneous foam phase. The equilibrium mean bubble diameter may be calculated with the critical Weber number [7].

The mixing capacity of each rotor-stator unit differs considerably. Two reasons can be pointed out. First, a change in blow ratio changes the effectiveness of air dispersion as a result of the altered stability of the foam. In general, the mixing capacity decreases with an increase in blow ratio. Eventually, the demixing rate will be nearly equal to the mixing rate, defining the maximum blow ratio in the mixer. Second, the hydrodynamics will change strongly as a result of the change in blow ratio. A change in the hydrodynamics will lead to a change in the mixing capacity of a rotor-stator unit.

In Fig. 5, an example of the orientation of the mixing characteristic as a function of the number of rotor-stator units installed in the mixer is given [8]. From this Figure it becomes evident that the increase in working space is proportional to the number of rotor-stator units. Based on this Figure, the blow ratio over twelve rotor-stator units as a function of the mixer height can be calculated. This has been done for two different liquid flows, and is given in Fig. 6. The path of the curve has been confirmed with samples taken from different locations in the mixer during foam production.

Since the blow ratio, and also the foam viscosity, will change considerably over the mixer height, the hydrodynamic behaviour of the foam will also change substantially over the mixer height. It is therefore necessary to study the mixing process in more detail.

The mixing in one rotor-stator unit is governed by the local process conditions. The mixing as a whole may then be viewed as a summation of the individual elements.

In relation to the parameters which determine the mixing in each mixing section, the following three comments may be made.

(1) In the rotor-stator unit, three velocities may be distinguished: the tangential velocity of the rotors, the axial velocity of the gas and foam phase, and the radial velocity of the foam phase between the rotors as a result of the centrifugal field.

Since the tangential velocity of the rotors is many 


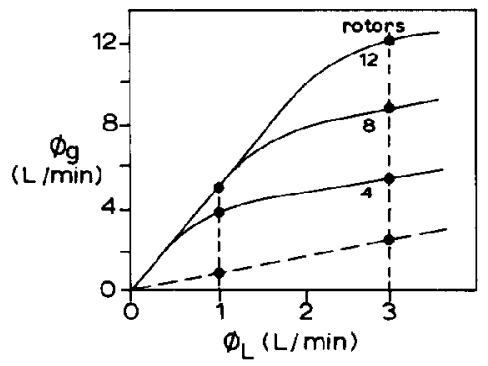

Fig. 5. Mixing characteristics.

times larger than the axial velocity of the gas and foam phase, the hydrodynamic behaviour is primarily determined by the velocity of the rotors. From the fact that when the number of rotor-stator units is increased the foaming capacity increases proportionally [8], it may be deduced that the axial dispersion does not substantially influence the hydrodynamics of the mixing process.

The velocity in the radial direction, resulting from the centrifugal field, causes a circulatory flow between rotor and stator. It seem that this circulation is of particular importance in keeping the foam phase homngenenus in the radial direction.

It will become clear that the foaming process is determined largely by the hydrodynamics, which can be characterized by the dimensionless Reynolds number, based on the rotor velocity and the properties of the foam phase.

(2) Even though in most cases the axial mixing of the foam flow is rather limited and the flow may be described with a plug flow model, the limited axial mixing may have a major influence on the mixing process. The axial mixing decreases the range of the blow ratios present in the mixer. A change in the blow ratio range will cause a change in the range over which the Reynolds number varies in the mixer. In some cases, this just may or may not shift the flow to an unfavourable flow regime. We shall return to this phenomenon later. The rate of backmixing in the rotor-stator mixer during production also depends on the location in the mixer, since the axial velocity of the foam flow increases over the mixer height. The axial backmixing may be characterized by the residence time distribution occurring in the flow of a liquid or foam phase through the mixer. The axial dispersion may be represented either by the Bodenstein number or by a cascade of $n$ ideally stirred tank reactors in series [9]. A measured number for ideally stirred tanks varies from \pm 2 to \pm 8 . The number of ideally stirred tanks increases with increase in flow rate, blow ratio and viscosity and decrease in rotational speed.

(3) The variables which are of primary importance in studying the mixing process per section are the geometry of the unit cell, the rotational speed, and the properties of the homogeneous foam phase at the given local blow ratio. The local foaming capacity, which is determined by the hydrodynamics

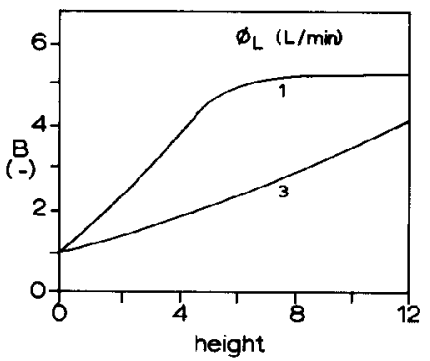

Fig. 6. Blow ratio of the foam as function of the height in the mixer.

and the stability properties of the foam, will primarily be a function of these properties. The hydrodynamics in particular will be described in more detail and will be characterized by power measurements.

\subsection{Energy dissipation in rotor-stator mixers}

Power input to mixers for the production of foam is an important design parameter and can also be used to characterize the hydrodynamics in the mixer. It is generally determined by measuring the torque of the shaft between motor drive and mixing apparatus. Power input is calculated from the torque by multiplying by the rotational speed $N$ :

$P_{0}=2 \pi N T$

It is well known that power consumption in continuous mixing can be expressed by the dimensionless power number $\mathrm{Ne}$ (Newton number):

$\mathrm{Ne}=P_{0} / \rho N^{3} D^{5}$

The Newton number depends on the Reynolds number

$\operatorname{Re}=\rho N D^{2} / \eta$

The Newton-Reynolds relation may therefore be expressed as

$\mathrm{Ne}=\mathrm{f}(\mathrm{Re})$

Relation (5) depends on the flow region, and is therefore different for the laminar and turbulent regions. In our investigation, the procedure in establishing the Newton-Reynolds relationship for foams in rotor-stator mixers was as follows.

(1) Measurements of power inputs were carried out on the geometries $1-8$ using glycerol-water mixtures of different viscosities. All the experiments were evaluated, and the results were correlated into one Newton-Reynolds relation.

(2) The mixers were flooded with homogeneous foam, and measurements of power inputs were carried out again. Based on the results, a relationship between the flow of foam and the flow of a Newtonian glycerol-water mixture could be determined [7].

(3) With a knowledge of the foam density and the foam viscosity, the actual energy dissipation was calculated based on steps (1) and (2). Also, the 
hydrodynamics was determined by calculating the Reynolds number for a given location in the mixer.

\subsubsection{The Newton-Reynolds equation for glycerol-} water mixtures

To measure the energy input in a rotor-stator mixer, diverse glycerol-water mixtures were used. The parameters varied in the experiments were: liquid viscosity $\left(\eta_{1}=1.5 \mathrm{~Pa} \mathrm{~s}, \eta_{2}=0.15 \mathrm{~Pa} \mathrm{~s}, \quad \eta_{3}=\right.$ $\left.0.02 \mathrm{~Pa} \mathrm{~s}, \eta_{4}=0.002 \mathrm{~Pa} \mathrm{~s}\right) ;$ rotational speed ( $500-$

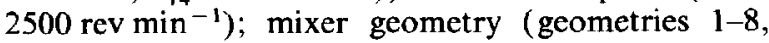
see Table 2).

Based on the results of these measurements, the definitions of the Newton and Reynolds numbers were adapted to the geometry of the mixer. A correlation factor $f$ was introduced to describe the Reynolds number independent of the geometry:

$\mathrm{Ne}=P_{0} z / \rho_{\mathrm{s}} D^{4} N^{3} h L q$

$\operatorname{Re}^{*}=\rho_{\mathrm{s}} N D p / \eta$

$f=71 o / q+553 p / \sqrt{D} q$

The Reynolds number may also be written as $\operatorname{Re}=\operatorname{Re}^{*} / f$.

Subsequently, the Newton number was plotted against Re. The resulting graph is shown in Fig. 7. A distinction between the laminar and turbulent regions of flow may now be made.

In the turbulent region, the following relation holds:

$\mathrm{Ne}=17$ for $\quad \operatorname{Re}>0.1$
In the laminar region,

$$
\mathrm{Ne}=\mathrm{Re}^{-1} \quad \text { for } \quad \mathrm{Re}<0.02
$$

In the region $0.02<\operatorname{Re}<0.1$, the flow changes from turbulent to laminar.

The measurements give rise to the following conclusions with respect to the dependence of the power consumed and the mixer geometry.

(i) The power dissipated in the liquid in the turbulent region is proportional to:

- the number of rotor-stator units, $h$;

- the number of pins on a rotor-stator unit, $i$;

- the facial area of a rotor pin, $L q$.

The power is independent of the distance between a rotor and stator pin, $p$.

The relationship thus determined is approximately analogous to the relationships valid for Rushton turbine stirrers [10].

(ii) In the correlation of the results in the laminar region, two terms which contribute to the energy dissipation were combined:

(a) flow of the medium around the pins of a rotor, in analogy to the equation for turbine stirrers [10]:

$\mathrm{Ne}=\left(\operatorname{Re}^{*}\right)^{-1} 553 \rho / \sqrt{D} q$

(b) flow between the rotors and stators, analogous to the flow between two rotating disks. This may be determined analytically. When this term is multiplied by the occupied fraction $o / z$ of the circular surface, the following equation is obtained:

$\mathrm{Ne}=\left(\mathrm{Re}^{*}\right)^{-1} 710 / q$

The constant in eqn. (12) follows directly from the

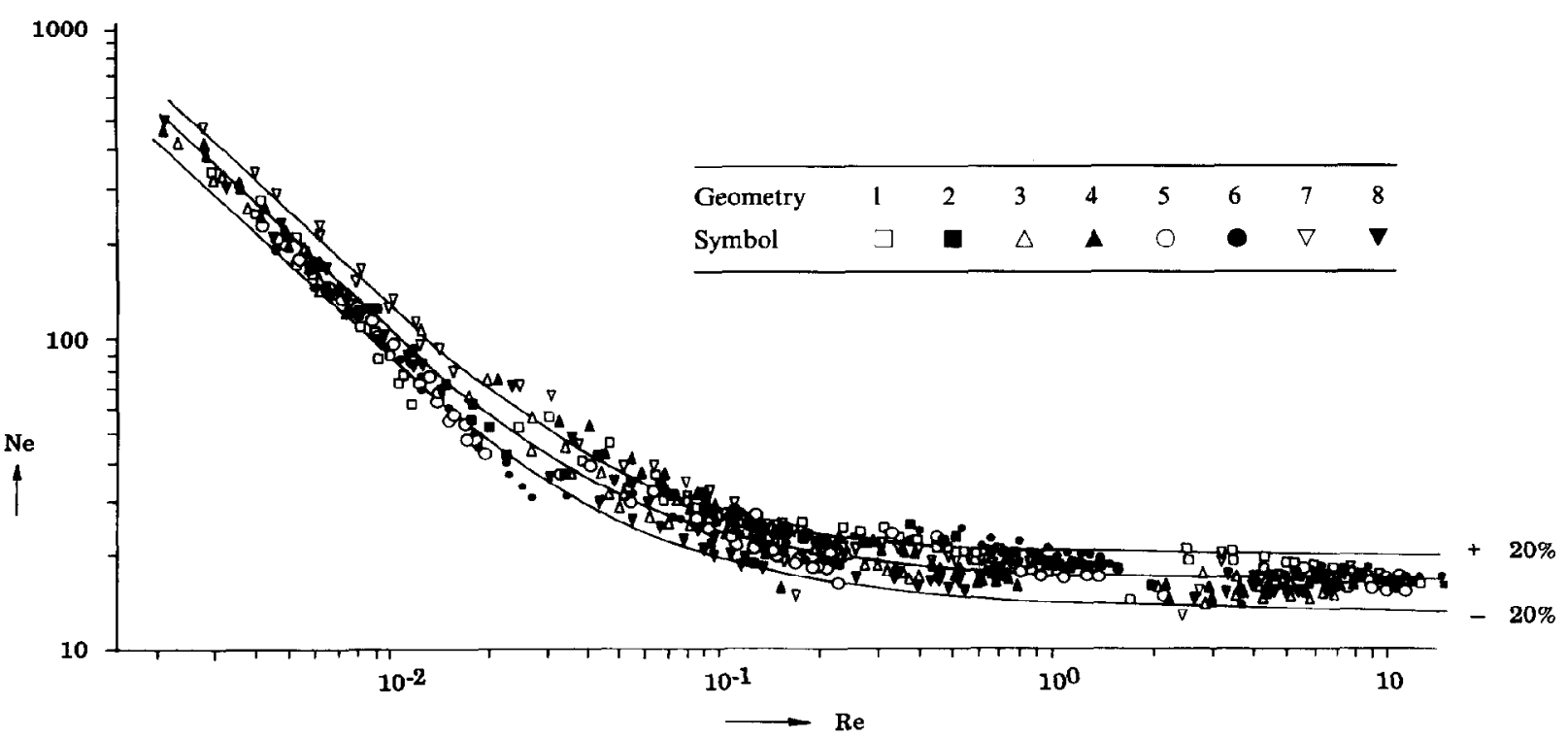

Fig. 7. Newton-Reynolds relationship. 
calculation, while the constant in eqn. (11) is fit based on the measurements. From the correlated equation in the laminar region it becomes evident that the power consumed by the liquid is:

- proportional to the number of rotor-stator units, $h$;

- nearly proportional to the number of pins on a rotor per rotor-stator unit (the pins on a rotor have a limited influence on each other (see Fig. 7));

- dependent on the pin height $q$, the distance $p$ between the rotor and stator, and the width of a pin $o$.

\subsubsection{Flow of foam in a rotor-stator mixer}

The flow of foam in a rotor-stator mixer can be described by the Newton-Reynolds relation, when certain adjustments are made to the Newton and Reynolds numbers:

- for the foam density, the mean density of the homogeneous foam phase must be used [7];

- for determining the correct apparent viscosity of the foam, the following procedure may be followed.

The rheology of the foam may be described by means of the power law [11]. This results in the following relation giving the apparent viscosity as a function of the shear rate:

$\eta=k D_{\mathrm{r}}{ }^{n-1}$

Subsequently, a mixer constant is defined which gives the relation between the mean shear rate in the mixer and the rotational speed of the mixer [7]. Now the apparent viscosity in the mixer may be calculated as

$\eta=k(K N)^{n-1}$

By measuring the mixer number $K$ for each geometry according to the method described by Metzner and Otto, the Newton-Reynolds relation becomes suitable for pseudoplastics, such as foams $[7,12]$.

The mixer constants $K$ were determined experimentally for the different geometries, and are given in Table 3. The margin of error $( \pm 30 \%)$ at the end of the entire experimental procedure leads to mixer constants with limited accuracy. This results in an error of about $15 \%$ when the Reynolds number is calculated using a fluid with an $n$-value of 0.5 .

TABLE 3. Mixing constants $K$

\begin{tabular}{lllllllll}
\hline Geometry & 1 & 2 & 3 & 4 & 5 & 6 & 7 & 8 \\
Mixer constant & 85 & 77 & 65 & 46 & 46 & 54 & 55 & 69
\end{tabular}

\subsubsection{Determination of the energy dissipation} and Reynolds numbers in the mixer under production circumstances

In an operating foam mixer, the blow ratio of the foam mixer will vary over the mixer height. The Reynolds and Newton numbers therefore have to be locally defined, and the overall energy dissipation is the summation of the energy dissipations in each rotor-stator unit. The Newton and Reynolds numbers can only be calculated if knowledge concerning the change of the foam density and foam viscosity over the mixer height is available. It is therefore only possible to characterize the Reynolds numbers after measurements are taken. The relation between the rheology and the foam structure must also be known prior to characterization. The rheology is primarily determined by the blow ratio, the bubble diameter distribution, and the viscosity of the liquid used [11]. The assumption is made that the presence of a continuous gas phase during process conditions influences the Newton and Reynolds numbers only to a negligible extent.

\section{The influence of the flow behaviour on the foaming process}

\subsection{General}

The rate of foam formation appears to depend strongly on the local flow behaviour in the mixer. In this section, the foaming process will be analysed with regard to the hydrodynamics appearing in the mixer. The range covered by the Reynolds number depends on the process variables primarily involved. When the mixer geometry and rotational speed are fixed, the change in Reynolds number over the mixer height will depend on the viscosity of the liquid or the dispersion, the rate of the foaming process, and the flow rates of the gas and liquid feeds. The Reynolds numbers can only be determined if the properties of the foam in the mixer are known.

The following overview is deduced from a great number of mixing characteristics measured under various process conditions, and from the investigation of the two-phase flow in a Perspex, one rotormixer unit. By observing the stationary behaviour of flow in a Perspex, one rotor-mixer unit, the formation of an air conus and a cavity in the back of the pins could be visualized (for the geometry of the one rotor-mixer, see ref. 7). It appeared that the mechanism of foam formation, and the influence of the process parameters such as rotational speed and mixer geometry, strongly depend on the values of the Reynolds numbers. A distinction can be made between the mechanism of dispersion appearing in the turbulent region and that appearing in the laminar region. The mechanism of dispersion in the turbulent region is dominant primarily at Reynolds numbers $0.1-0.2$ and upwards, and that in the laminar region primarily at Reynolds numbers less than $0.015-0.03$. In considering the complete Reynolds region, three flow regions can be distinguished, as shown in Table 4.

In this research, the rate of foam formation as a function of the various process parameters has been studied phenomenologically, and no description is made of the exact flow as a function of the different process parameters. We shall limit ourselves to a short characterization of the two types of dispersion 
TABLE 4. Flow regions for different Reynolds numbers

\begin{tabular}{llll}
\hline Flow region & Reynolds number & Mixing & $\begin{array}{l}\text { Type of } \\
\text { mixing }\end{array}$ \\
\hline Turbulent & $>0.15$ & Good & $\begin{array}{c}\text { Turbulent } \\
\text { dispersion }\end{array}$ \\
$\begin{array}{l}\text { Transition } \\
\text { Laminar }\end{array}$ & $\begin{array}{l}0.02<\operatorname{Re}<0.15 \\
<0.02\end{array}$ & $\begin{array}{l}\text { Poor } \\
\text { Moderate }\end{array}$ & $\begin{array}{c}\text { Laminar } \\
\text { dispersion }\end{array}$ \\
\hline
\end{tabular}

mechanism that can appear, and the influence of the various process parameters on the dispersion (such as rotational speed and mixer geometry). The rate determining step seems to be the rate at which air from the cavity behind the pins can be dispersed in the foam phase.

\subsection{Laminar dispersion}

From the cavity at the back of the pins, gas is dispersed into the foam phase. The flow around the rotor pins receives, as a result of the presence of the stator pins, a pulse. Because of the pulsed flow, the cavity at the back of the pins therefore depends on the position of the rotor with respect to the stator. If the cavity increases, air is fed to it from the air conus around the central axis. When a rotor pin passes a stator pin, a fraction of the air from the cavity will be dispersed in the foam phase. At a Reynolds number larger than 0.02 , the force applied to the bubble is insufficient to achieve fractionation. An increase in rotational speed leads to a greater rate of dispersion under the laminar flow conditions. Furthermore, this view gives a satisfactory answer to the differences in dispersion in the laminar region when different mixer geometries are used. In this region of flow the rate of dispersion seems to depend strongly on the distance between the rotors and stators, $p$. With a decrease in this distance the rate of dispersion increases rapidly, owing to the increased intensity of pulsation of the flow around the rotor pins. The rate of foam formation also increases with decreasing pin height $q$. This is due to improved flow of the foam around the cavity, allowing better fractionation of the air from the cavity.

\subsection{Turbulent dispersion}

In the turbulent region, the rate of foam formation decreases slightly with increasing rotational speed. The centrifugal field present probably causes the decreasing mixing capacity at higher rotational speeds. The mixing takes place through the formation of a cavity at the back of the pins, from which bubbles are fractionated. In the absence of a centrifugal field it may be expected that the mixing capacity increases with increasing flow velocity. With an increase in the centrifugal field, however, the cavity will have the tendency to remain around the axis, thus making the fractionation more difficult.
The mixing as described here appears at Reynolds numbers greater than $0.1-0.2$. Around these Reynolds numbers, mixing changes rather abruptly. At Reynolds numbers less than $0.1-0.2$, the rate of dispersion is small, being caused by the appearance of a stagnant cavity at the back of the pins which cannot be broken up and dispersed in the absence of turbulent eddies.

Owing to the influence of the centrifugal field, this transition is not given by one fixed Reynolds number. This transition Reynolds number is, among other things, dependent on the rotational speed. A larger rotational speed results in a larger transition Reynolds number. At a rotational speed of about $1200 \mathrm{rev} \mathrm{min}^{-1}$, the transition appears at a Reynolds number of about 0.015 .

The foaming capacity is nearly independent of the distance between the rotors and the stators. Obviously the dispersion of the air is determined more by the eddies at the back of the pins than by the pulsation, which appears when a rotor pin passes a stator pin. From the measurements of the rate of foam formation as a function of the pin geometry, it seems that square pins work better than other geometries.

The bad mixing in the transition region is caused by the absence of both mechanisms of dispersion. At both sides of this region, a rather definite transition is found to better mixing.

\section{Examples of the influence of the diverse variables on the mixing characteristic}

The influence of a number of variables, such as rotational speed and mixer geometry, as was described earlier, will be explained in more detail with a few examples of liquid systems that are foamed in the rotor-stator mixer (see Table 2).

Three liquid systems with different viscosities and foaming properties are chosen. The mixing characteristics are determined at rotational speeds of 500 $2500 \mathrm{rev} \mathrm{min}^{-1}$.

(1) With the system Ls-30, the influence of the pin height and the distance between the rotor and stator will be pointed out (the flow region lies in the laminar-transition region).

(2) With the systems Ls-30 (good foaming properties) and $\mathrm{Di}-40$ (poor foaming properties), a comparison is made of two liquid systems with different foaming capacities. The foaming flow region for both systems lies in the transition-laminar region.

(3) Foam formation of a poor foaming, nonthickened system results in a mixing characteristic corresponding entirely to the turbulent flow region. This is shown in the examples of the mixing characteristic of the system Di-0.

A selection of mixing characteristics is represented in Figs. 9-12. In Fig. 8 the corresponding Reynolds ranges over the mixer are plotted for six combinations of mixer geometry and liquid systems for a small and a large flow rate. The minimum Reynolds 


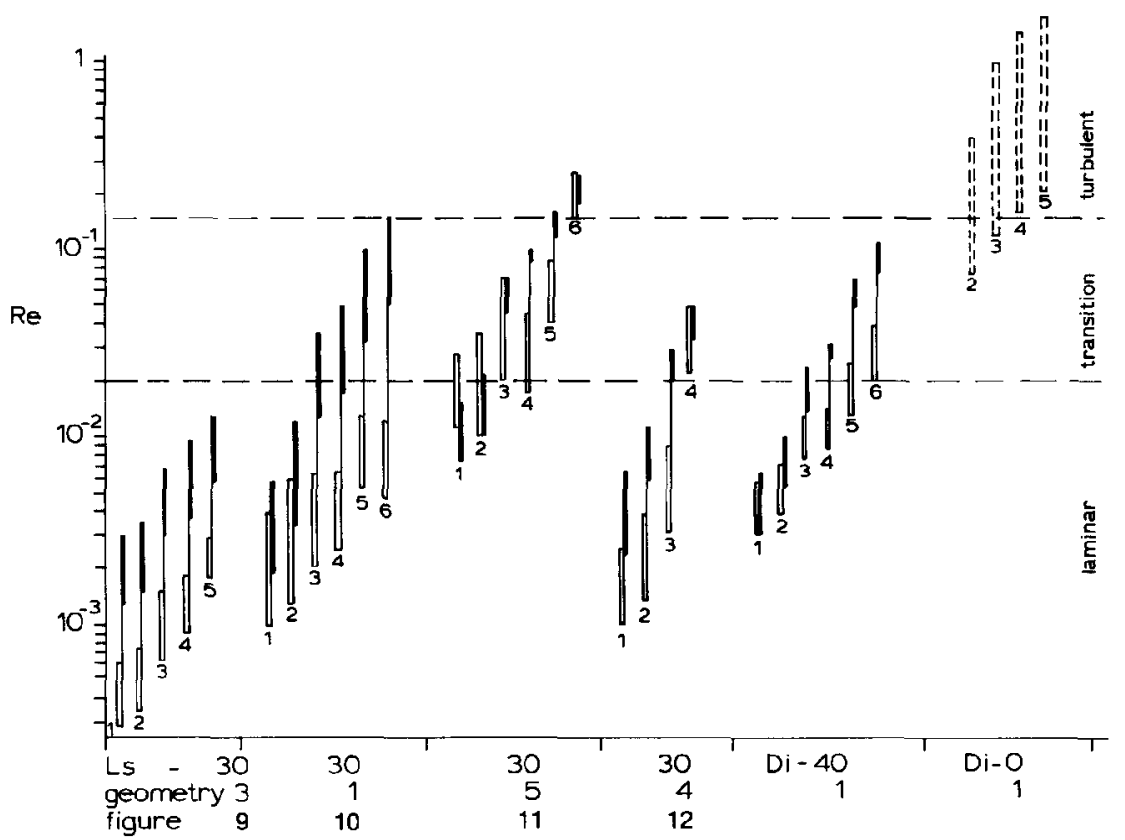

Fig. 8. Reynolds number ranges over the mixer: $\square$, Re range for $F_{\mathrm{L}}=21 \mathrm{~min}^{-1} ; \square$, Re range $F_{\mathrm{L}}=0.2 \mathrm{I} \mathrm{min}^{-1}$; rotational speed $\left(\right.$ rev $\left.\min ^{-1}\right): 1,450 ; 2,600 ; 3,950 ; 4,1200 ; 5,1800 ; 6,2400$.

number can be determined from the properties of the foam leaving the mixer, and the maximum Reynolds number can be estimated from the properties of the foam in the bottom of the mixer. The density of the foam in the bottom of the mixer has been measured for a number of cases, and in other cases it was estimated. The estimation is based on the knowledge of the general gradual change of the blow ratio over the entire mixer.

The viscosities of the foam in the mixer depend on the viscosities of the liquids used, the blow ratio and the bubble diameter distribution. They were measured in a coaxial rotational viscosity meter [7]. A number of the experiments performed will be described in more detail.

Foam formation of Ls-30 in mixer geometry 3 $(p=1 \mathrm{~mm}, q=15 \mathrm{~mm})$ (Fig. 9)

The mixing characteristics of Fig. 9 are typical for a foaming process which lies entirely in the laminar flow region and takes place under laminar conditions. It becomes apparent from Fig. 8 that the Reynolds number in all cases is less than 0.02 . With increasing rotational speed, the foam formation increases and all mixing characteristics have more or less similar shapes.

Foam formation of Ls-30 in mixing geometry 1 $(p=I \mathrm{~mm}, q=3 \mathrm{~mm}$ ) (Fig. 10)

The mixer geometry 1 results in a lower mixing capacity for the system Ls-30 than geometry 3 . The foaming process takes place entirely in the laminar region at small rotational speeds, but shifts with increasing rotational speed towards and into the transition region. For this reason, the mixing characteristics do not follow a path analogous to that in Fig. 9 where the mixing capacity does increase with increased rotational speed. At higher rotational speeds, the mixing process takes place partly in the laminar flow region and partly in the turbulent region. An explanation of the peculiar curve of the mixing characteristic at $2400 \mathrm{rev} \mathrm{min}^{-1}$ is the following. At low flow rates, mixing occurs primarily in the laminar region as a result of the rapid increase of the blow ratio in the mixer. At higher flow rates and first

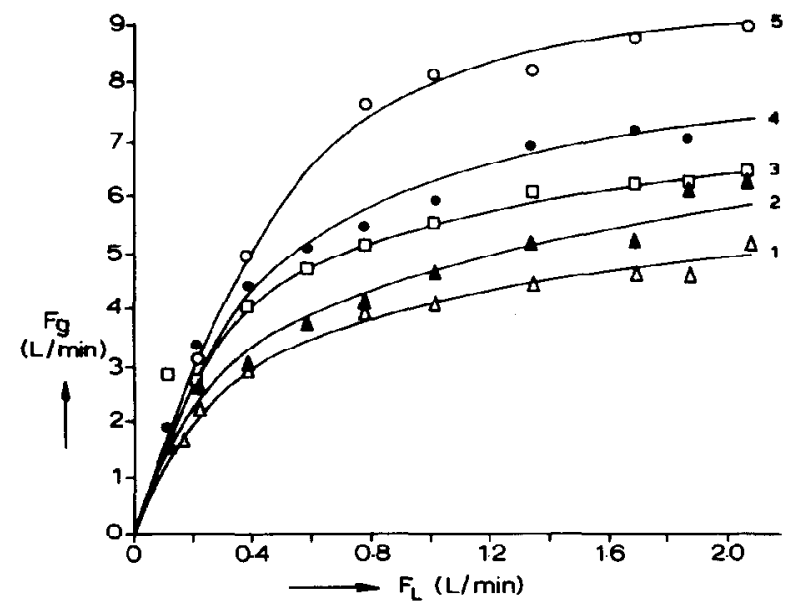

Fig. 9. Characteristics of Ls-30 in geometry 3 (indices in Fig. 8). 


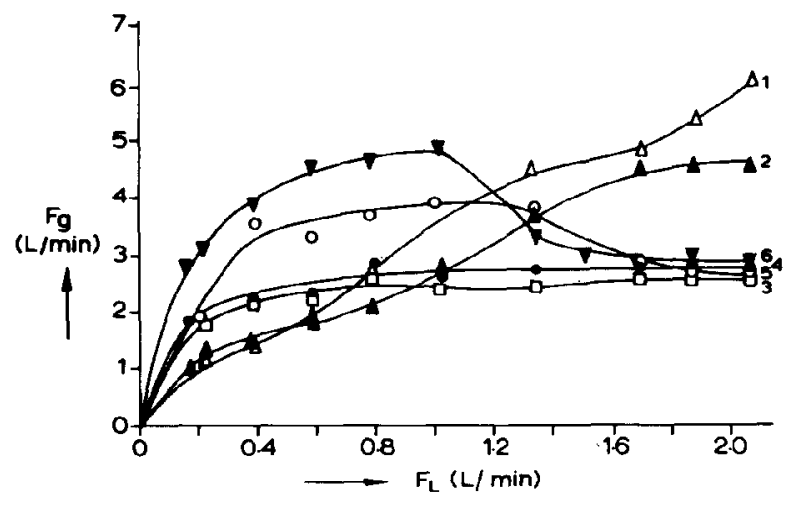

Fig. 10. Characteristics of Ls-30 in geometry 1 (indices in Fig. 8).

in the bottom of the mixer, the flow region changes by shifting to the transition region, where foam formation is much poorer. This decreased rate of foam formation in the bottom of the mixer causes an accelerated approach to the transition region in the remainder of the mixer. This results in the sharp drop in foam formation.

Foam formation of $L s-30$ in mixing geametry 5 $(p=1 \mathrm{~mm}, q=4.5 \mathrm{~mm})$ (Fig. 11)

The mixing capacity of geometry 5 is noticeably lower than the capacities of geometries 3 and 1. The mixing process takes place partly in the transition region. The geometry leads to poor mixing in that part which lies in the laminar region as well as in part which lies in the transition region.

It is evident that the mixing process becomes poorer from Fig. 9 to Fig. 11. The decrease is due on the one hand to the shift in Reynolds numbers towards the transition region, and on the other hand to the poorer mixing properties of the rotor-stator units with higher pin height $q$.

Foam formation of $L s-30$ in mixing geometry 4 $(p=2 \mathrm{~mm}, q=1.5 \mathrm{~mm})$ (Fig. 12)

The results of the measurements show that the rate of foam formation is less than that with geometry 3 (Fig. 9). The Reynolds number changes somewhat towards the transition region with an increase in the distance between the rotor and stator pins, but the mixing capacity over the entire flow region in which mixing takes place decreases (transitional and laminar flow). The mixing effectiveness decreases strongly with increased pin distance $p$.

\section{Foam formation of $\mathrm{Di}-4 \mathrm{O}$ and $\mathrm{Di}-\mathrm{O}$ in mixing geometry 1}

The Reynolds ranges of both foaming processes are given in Fig. 8. The corresponding mixing characteristics are not represented in this article (see ref. 13). System Di-40 foams worse than system Ls-30.

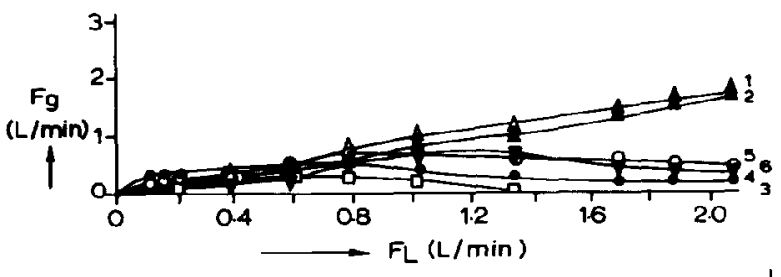

Fig. 11. Characteristics of Ls-30 in geometry 5 (indices in Fig. 8).

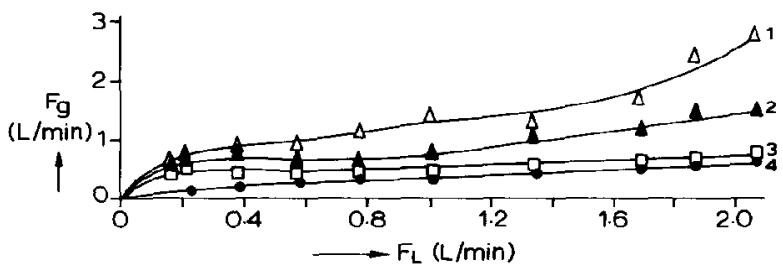

Fig. 12. Characteristics of Ls-30 in geometry 4 (indices in Fig. 8).

Because the Reynolds ranges lies in the same region as that of Ls-30 the mixing characteristics are similar to those of Fig. 10, but on a lower level.

System Di-0 foams completely in the turbulent flow region. An example of one mixing characteristic is given in Fig. 3.

\section{Conclusion}

In this article several aspects have been treated concerning the influence of the hydrodynamics of the foaming process in a rotor-stator mixer.

Although the picture is certainly not complete, the general description of the foaming behaviour reported here gives a better understanding of the foaming process.

\section{Acknowledgement}

This investigation was supported (in part) by the Netherlands Foundation for the Technical Sciences (STW), future Technical Science Branch of the Netherlands Organization for the Advancement of Pure Research (ZWO).

\section{Nomenclature}

$\begin{array}{ll}B & \text { blow ratio } \\ D & \text { head diameter of mixer, m } \\ D_{\mathrm{r}} & \text { shear rate, } \mathrm{s}^{-1} \\ F_{\mathrm{L}}, F_{\mathrm{G}} & \begin{array}{l}\text { liquid and gas flow rates, } 1 \mathrm{~min}^{-1} \\ i\end{array} \\ h & \text { number of mixing pins per rotor } \\ K & \text { number of installed rotor-stator units } \\ k & \text { mixer constant } \\ L & \text { rheological value } \\ n & \text { diameter of annular mixing space } \\ N & \text { rheological value } \\ & \text { rotational speed, } \mathrm{s}^{-1}\end{array}$

$B$ blow ratio

$F_{\mathrm{L}}, F_{\mathrm{G}}$ liquid and gas flow rates, $1 \mathrm{~min}^{-1}$

$i$ number of mixing pins per rotor

$h$ number of installed rotor-stator units

$K \quad$ mixer constant

$k$ rheological value

$n \quad$ rheological value

$N \quad$ rotational speed, $\mathrm{s}^{-1}$ 
$\mathrm{Ne} \quad$ Newton number

$o \quad$ width of mixer pin, $\mathrm{m}$

$P$ pressure, $\mathrm{N} \mathrm{m}^{-2}$

$P_{0} \quad$ power supplied to mixer, $\mathrm{kg} \mathrm{m}^{2} \mathrm{~s}^{3}$

$p \quad$ distance between rotor and stator blade, $\mathrm{m}$

$q \quad$ height of mixer pin, $\mathrm{m}$

Re Reynolds number

$T$ torque, $\mathrm{kg} \mathrm{m}^{2} \mathrm{~s}^{-2}$

$z=2 n d / i$, distance between rotor pins, $\mathrm{m}$

$\eta \quad$ viscosity, $\mathrm{N} \mathrm{s} \mathrm{m}^{-2}$

$\rho_{\mathrm{s}} \quad$ foam density, $\mathrm{kg} \mathrm{m}^{-3}$

\section{References}

1 T. F. Cooke, Text. Chem. Color., 15 (5) (1983) 74.
2 T. L. Dawson, J. Soc. Dyers Colour., 97 (1981) 262.

3 J. D. Jones, Turner and Snyder, Text.-Ind., (Oct.) (1984) 25.

4 A. J. De Vries, Ph.D. Thesis, Univ. Delft, 1957.

5 G. Knauf, Ph.D. Thesis, Univ. Stuttgart, 1983.

6 A. J. Bikerman, Foams, Springer-Verlag, Heidelberg, 1973.

7 A. B. J. Kroezen and J. Groot Wassink, J. Soc. Dyers Colour., 103 (1987) 386-393.

8 A. B. J. Kroezen and J. Groot Wassink, J. Soc. Dyers Colour., 102 (1986) 397.

9 Beek and Mutzall, Transport Phenomena, Wiley, Chichester, U.K., 1975.

10 F. P. O'Connel and D. E. Mack, Chem. Eng. Prog., 46 (1959) 358.

11 A. B. J. Kroezen and J. Groot Wassink, J. Soc. Dyers Colour., 104 (1988) 393-400.

12 A. B. Metzner and R. E. Otto, AIChE J., 3 (1957) 3.

13 A. B. J. Kroezen, Ph.D. Thesis, Univ. Twente, 1988. 